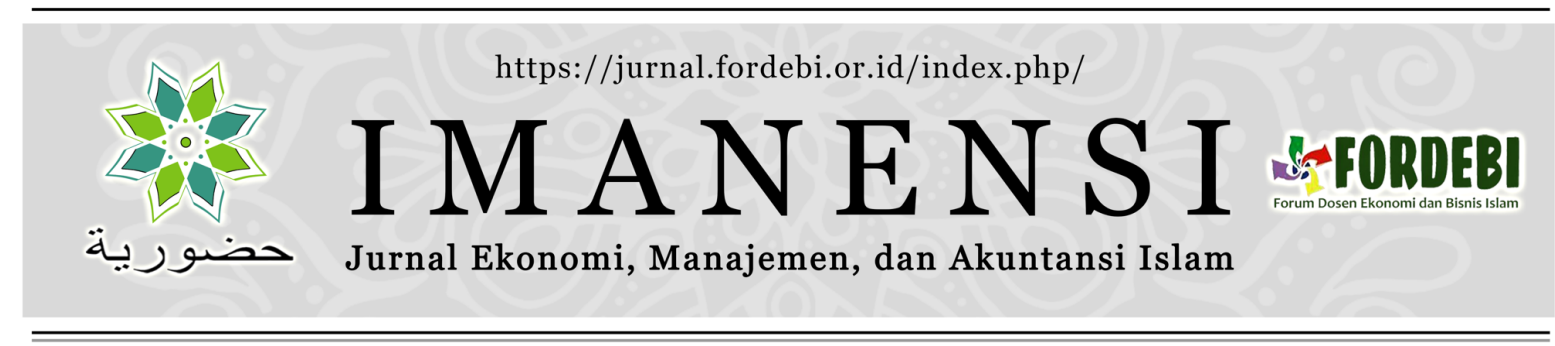

\title{
PROGRAM INKUBASI BISNIS SOLUSI PEMBERDAYAAN PEREMPUAN PRASEJAHTERA
}

\section{Lilis Ardinia,1*, Wiwiek Srikandi Shabrieb,2}

a,b Sekolah Tinggi Ilmu Ekonomi Indonesia Surabaya (STIESIA), Л. Menur Pumpungan No.30, Menur Pumpungan, Surabaya, Jawa Timur, 60118, Indonesia.

11ilisardini@stiesia.ac.id*; ${ }^{2}$ wiwieksrikandi@stiesia.ac.id

${ }^{*}$ Corresponding author

\begin{tabular}{ll}
\hline INFO ARTIKEL & Abstrak: Program Inkubasi Bisnis Solusi Pemberdayaan \\
IMANENSI & Perempuan Prasejahtera. Penelitian ini bertujuan untuk \\
Volume 6 & mengeksplorasi proses pemberdayaan perempuan prasejahtera \\
Nomor 1 & melalui program inkubasi bisnis. Penelitian menggunakan \\
Halaman $33-42$ & metode eksploratory pada perempuan prasejahtera di rumah \\
Malang, Maret 2021 & susun Romokalisari, Rusun Dupak Bangunrejo dan Rusun \\
ISSN: 2339-1847 & Pesapen. Hasil penelitian menunjukkan bahwa program \\
e-ISSN: $2683-9968$ & inkubasi bisnis dilakukan dengan pelatihan hard skill, soft skill, \\
Kronologi Artikel: & dan inovasi dengan cara differensiasi produk, keduanya dapat \\
Tanggal Masuk: & meningkatkan kemandirian dan penghasilan perempuan \\
26 November 2020 & prasejahtera di rumah susun.
\end{tabular}

Tanggal Revisi:

23 Februari 2021

Tanggal Diterima:

3 Maret 2021

Kata Kunci:

Inkubasi bisnis;

Inovasi;

Kemandirian

Penghasilan;

Keywords:

Business incubation;

Income;

Independence

Innovation;

\begin{abstract}
Business Incubation Program for Empowerment Solutions for Underprivileged Women. This study aims to explore the process of empowering underprivileged women through a business incubation program. The research used an exploratory method on underprivileged women in the Romokalisari flats, the Dupak Bangunrejo and Pesapen Flats. The results showed that the business incubation program was carried out by training on hard skills, soft skills, and innovation by means of product differentiation, both of which could increase the independence and income of underprivileged women in flats.
\end{abstract}

Disitasi sebagai: Ardhini, L., dan Shabrie, W.S. (2021). Program Inkubasi Bisnis Solusi Pemberdayaan Perempuan Prasejahtera. IMANENSI: Jurnal Ekonomi, Manajemen, dan Akuntansi Islam, 6(1), 33-42. https://doi.org/10.34202/imanensi.6.1.2021.33-42.

\section{PENDAHULUAN}

Pemberdayaan wanita menjadi salah satu sasaran strategis dalam meningkatkan status ekonomi keluarga. Hal ini dikarenakan, pendapatan seorang kepala keluarga saja belum cukup memenuhi kebutuhan keluarga. Salah satu jenis pemberdayaan yang dapat dilakukan adalah dengan melakukan inkubasi usaha mikro, yaitu suatu bentuk kegiatan untuk mendukung, memelihara, dan mengembangkan sektor-sektor usaha kecil dan menengah bahkan membentuk 
embrio-embrio baru untuk berkembang menjadi bentuk usaha yang mapan (Adegbite, 2001; Aernoudt, 2004; Fiegenbaum, 2015; Neumeyer \& Santos, 2018; Swayne, Mccarthy, \& Fisher, 2019). Tujuan program inkubasi adalah untuk meningkatkan bakat kewirausahaan. Pendorong perusahaan bisnis baru bukan hanya tergantung pada ketersediaan dana, fasilitas dan teknologi saja, melainkan pada pelaku usaha (Galvão, Marques, \& Ferreira, 2018; Markowska, 2018; Neumeyer \& Santos, 2018; Suharto \& Sugito, 2019; Swayne et al., 2019; Xu, 2010). Dalam meningkatkan pendapatan rumah tangga mereka, diperlukan motivasi dan usaha yang keras, sehinga tidak hanya keinginan saja tapi juga kemampuan, motivasi dan niat yang kuat didukung oleh modal yang cukup (Andrian et al., 2015; Ciptosari, Prabawa, \& Antonius, 2019). Modal utama yang harus dimiliki perempuan untuk memulai berwirausaha adalah niat. Niat berwirausaha sangat efektif untuk memprediksi dan menjembatani antara sikap seseorang terhadap kewirausahaan dengan perilaku kewirausahaannya (Galvão et al., 2018; Markowska, 2018).

Penelitian sebelumnya menyebutkan bahwa pemberdayaan melalui usaha mikro mampu meningkatkan pendapatan keluarganya (Handayani, Ardini, \& Damayanti, 2016; Suharto \& Sugito, 2019). Namun, disisi lain terdapat tantangan yaitu kerampilan yang dimiliki perempuan prasejahteraterbatas karena tingkat pendidikan, tingkat ekonomi, tingkat umur, tingkat kematangan berumah tangga (Cassells \& Lewis, 2017; Permatasari, Utoyo, \& Sulasari, 2016). Usaha yang dijalankan dapat berlangsung terus-menerus jika produk yang dihasilkan berkualitas dan memenuhi standar pasar, produk unggulan yang diharapkan dapat bersaing di pasar menjadi bekal para pengusaha, perempuan rusun yang akan dilatih dengan fasilitas inkubasi usaha mandiri ini diharapkan akan menghasilkan produk-produk yang siap di pasar global (Healy \& Dwyer, 2018). Produk yang dihasilkan melalui fasilitas inkubasi usaha mandiri akan mendorong minat kewirausahaan, dan memberikan peran yang positif dengan terciptanya lapangan pekerjaan, meningkatkan pendapatan masyarakat, mengombinasikan faktor-faktor produksi (alam, tenaga kerja, modal dan keahlian) dan meningkatkan produktivitas nasional (Suarsa \& Sutajaya, 2015; Telagawathi, 2017).

Rumah susun warga disingkat rusunawa menjadi tempat hunian beberapa warga, kebanyakan warga yang tinggal di rusunawa adalah yang kesejahteraannya dibawah rata-rata atau yang berpenghasilan rendah (dibawah UMR). Penghuni rusun memiliki syarat-syarat tertentu yang telah diatur dalam Peraturan Menteri Negara Perumahan Rakyat Nomor 14 PERMEN/M/2007 tentang pengelolaan rumah susun sederhana. Dalam meningkatkan kesejahteraan warga di rusun, pemerintah Kota Surabaya telah membuat beberapa program dalam mengentaskan kemiskinan (Handayani et al., 2016). Upaya pemerintah Kota Surabaya dalam pemberdayaan perempuan melalui pelatihan untuk ibu rumah tangga seperti menjahit, membuat kue, maupun keterampilan handycraf dan keterampilan lainnya. Hal ini dilakukan dalam rangka terciptanya iklim usaha mandiri. Harapannya memberdayakan dilakukan untuk wanita supaya bisa memperoleh pendapatan tambahan (Citra, 2017; Suarsa \& Sutajaya, 2015; Telagawathi, 2017). Penelitian ini bertujuan untuk menjelaskan proses pemberdayaan yang dilakukan pada perempuan prasejahteradi rumah susun dalam rangka meningkatkan pendapatan keluarga.

\section{METODE}

Penelitian ini merupakan penelitian kualitatif eksplanatory untuk menjelaskan proses pemberdayaan yang dilakukan pada perempuan prasejahtera. Kategori perempuan prasejahtera dalam penelitian ini adalah perempuan miskin yang belum mampu membantu keluarganya, untuk memberikan penghasilan tambahan buat keluarganya. Teknik pengumpulan data yang digunakan adalah in-depth interview, 
observasi, dan dokumentasi. Teknik analisis yang dilakukan dalam penelitian kualitatif adalah dengan melakukan proses transkripsi, kategorisasi dan menentukan beberapa tema mulai dari model pemberdayaan, kegiatan inkubasi, manfaat inkubasi pada kemandirian dan pendapatan, dan inovasi.

Penelitian ini dilakukan di 3 wilayah rusun yang ada di Kota Surabaya, yaitu rumah susun Romokalisari, rumah susun Dupak Bangunrejo dan Rumah susun Pesapen. Objek penelitian adalah perempuan-perempuan yang tinggal di rumah susun yang mendapatkan pelatihan dasar pada inkubasi usaha mandiri. Target Peserta yang mengikuti pelatihan Inkubasi dan Klinik Usaha Mandiri adalah sebanyak 95 orang dengan perincian 59 orang berasal dari Rusun Romokalisari, 28 orang dari rusun Dupak Bangunrejo dan 8 orang dari rusun Pesapen.

\section{HASIL DAN PEMBAHASAN}

Dinas Pengendalian Penduduk, Pemberdayaan Perempuan dan Perlindungan Anak (DP5A) Kota Surabaya melakukan perubahan metode dan model kegiatan Pelatihan Ketrampilan Dasar untuk Keluarga Miskin dalam Pemberdayaan Ekonomi. Perubahan kegiatan tersebut dinamakan "Inkubasi dan Klinik Usaha Mandiri". Kegiatan ini dimaksudkan sebagai upaya memberikan tambahan kemampuan soft skill dan teknis dasar produksi bagi warga Kota Surabaya sebagai bekal pemberdayaan bagi warga kota dalam bentuk wirausaha untuk menambah pendapatan ekonomi keluarga.

\subsection{Model Pemberdayaan Perempuan Prasejahtera}

Pemberdayaan perempuan prasejahtera secara terpadu harus dirancang sedemikian rupa, sehingga dapat menjawab kebutuhan ibu - ibu rumah tangga itu sendiri, untuk mengembangkan kegiatan usahanya. Pemberdayaan terhadap ibu ibu rumah tangga tidak hanya berupa pelatihan saja, tetapi juga turunnya berbagai bantuan fasilitas usaha yang diharapkan dapat mendukung kelangsungan serta mempercepat perkembangan usaha ibu - ibu rumah tangga untuk menghasilkan pendapatan tambahan.

Model pemberdayaan perempuan prasejahtera di 3 rusunawa yaitu rusun Romokalisari, rusun Dupak Bangunrejo dan rusun Pesapen dapat dikategorikan memiliki tingkat kemampuan dalam meningkatkan penghasilan rumah tangga, perempuan prasejahtera ini mampu bersaing di pasar, memiliki motivasi yang tinggi dan kepercayaan diri terlihat dari cara mereka berpikir, inovasi, kreatif dan dari sikap serta pikiran positif dalam menyelesaikan setiap masalah. Tahap mendapatkan kerangka model pemberdayaan perempuan prasejahtera dalam meningkatkan penghasilan keluarga (Gambar 3), dimulai dengan mengumpulkan data yang disebarkan di 3 rusunawa sebagai dasar mengundang wanita rusun untuk pelatihan.

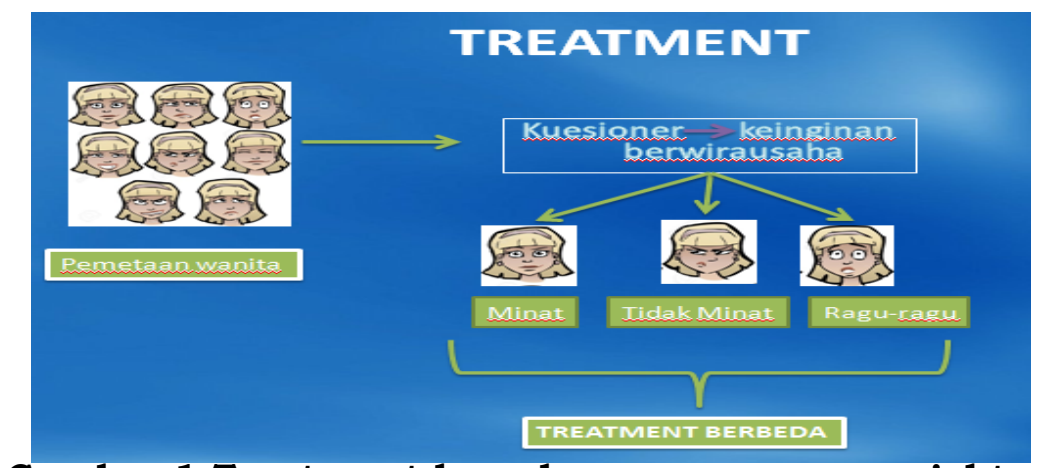

Gambar 1 Treatment kepada perempuan prasejahtera 
Penyebaran kuisioner dilakukan untuk mengidentifikasi minat peserta dalam rangka pembuatan klaster peserta. Selanjutnya dilakukan metode treatment untuk menguatkan mental perempuan prasejahtera terutama dalam memotivasi diri dan pola berpikir. Penguatan mental sangat membantu para peserta inkubasi mandiri karena budaya yang terbentuk selama mereka tidak bekerja atau berpenghasilan minimum bahkan termaginalkan akan merubah pola pikir mereka menjadi perempuan yang percaya diri, bersikap dan mampu bersaing di dunia bisnis/kerja. Peran keluarga sangat dibutuhkan saat treatment ini dilakukan terutama peran suami dan anak (Lihat Gambar 1 dan 2)

Kemampuan hard skill yang belum dimiliki akan sangat mudah diterima karena kebiasaan untuk bekerja telah dimiliki, sedangkan kemampan soft skill sangat dibutuhkan ketekunan, kerajinan dan ketelitian. Sehingga akan terbentuk sebuah model pemperdayaan yang di inginkan

\subsection{Kegiatan Inkubasi Mandiri di 3 Rusunawa}

Kegiatan ini bertujuan untuk mengintegrasikan program pemberdayaan dalam upaya meningkatkan pendapatan keluarga melalui usaha mandiri yang dilakukan oleh ibu-ibu rumah tangga yang ada di lingkungan rusunawa. Dengan meningkatnya pendapatan keluarga melalui usaha mandiri diharapkan dapat mewujudkan keluarga yang sejahtera secara finansial.

Salah satu informan dalam penelitian ini adalah ibu Ana Widayati, menyatakan hal yang sangat positif dalam kegiatan inkubasi, bahkan dia juga menyatakan bahwa dia telah menulari keahliannya kepada sesama perempuan prasejahtera.

"Aku yoo ngajari ke konco-konco sing cedek, ben iso buat brownieskoyo aku bu,,,wong gak susah to, sing penting itu niatnya pasti iso,,, iso (sambil tangannya di kapal-kepalkan seperti gregetan)"

Beliau mendapatkan pelatihan membuat brownies dari Program Inkubasi DP5A. Dalam pelatihan tersebut, beliau di dampingi oleh Ibu Ningsih selaku inkubator, instruktur dan motivator. Pelatihan dilakukan dua kali setiap minggu yang berlokasi di Pendopo Rusun Dupak Bangunrejo mulai pagi sampai menjelang siang. Adapun untuk bahan dan peralatan selama pelatihan membuat brownies, sudah disiapkan dan disediakan oleh Ibu Ningsih.

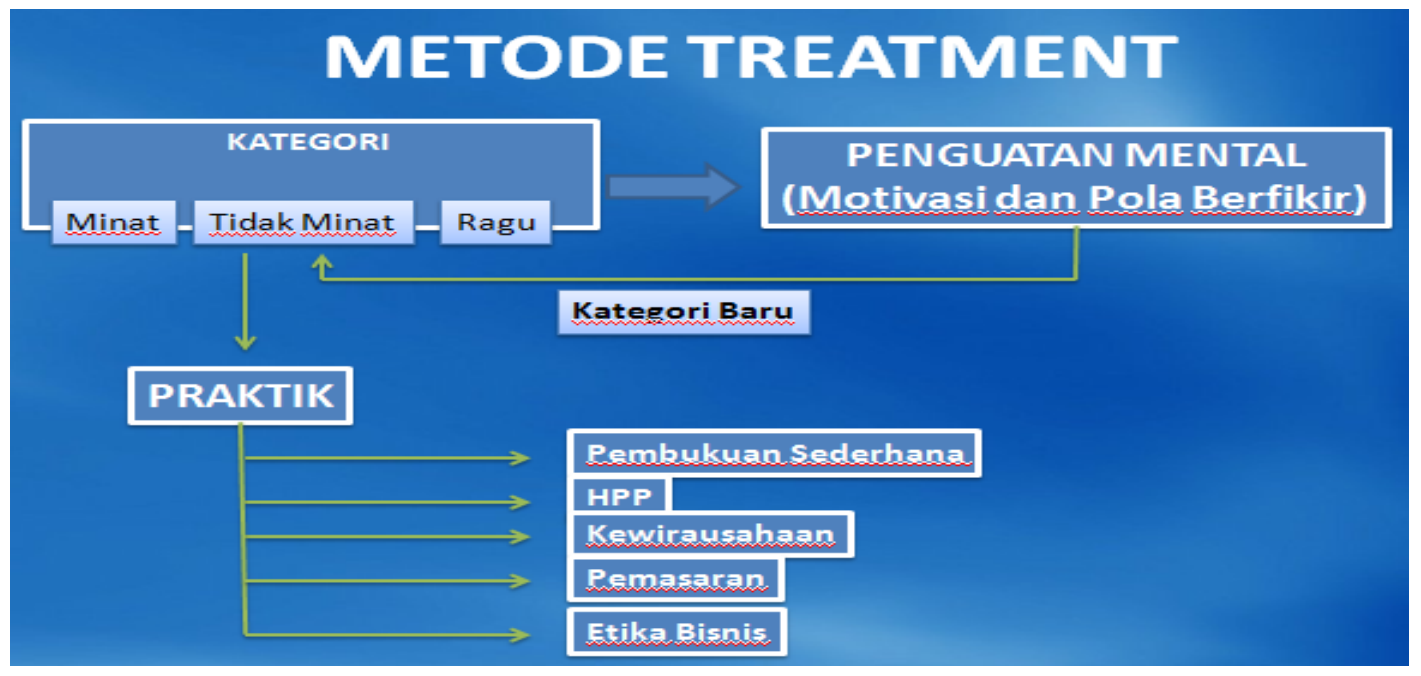

Gambar 2. Metode Treatment 
Selama pelatihan membuat brownies, Ibu Ningsih memberikan banyak ilmu mengenai tatacara membuat kue brownies. Ibu-Ibu rusun diajari bagaimana membuat adonan kue yang benar, menghias kue yang bagus agar bisa menarik pelanggan dan bagaimana membuat varian brownies. Ibu-ibu rusun merasa senang karena alat dan bahan seperti oven, bahan membuat kue dan sebagainya sudah disediakan sehingga ibu-ibu langsung bisa mempraktekan langsung bagaimana cara membuat brownies.

Selain itu, Ibu Ana juga mendapatkan manfaat lain selama mengikuti pelatihan inkubasi yaitu mendapatkan ilmu tentang pembukuan sederhana dan manajemen keuangan. Beliau sekarang sudah mempraktekkan pembukuan sederhana dan manajemen keuangan dalam kegiatan bisnisnya.

"diajari debet kredit yoo awalnya pusing..lama-lama ngerti,,,intine kongkon nulis smua transaksi,ojo ngandalno ingetan,,mergo akeh sing diiling,,hahahaha.”.

Selain pelatihan hard skill yang diberikan, pelatihan soft skill juga diberikan, seperti membuat pembukuan sederhana dan manajemen keuangan, pelatihan ini sangat membantu para perempuan prasejahtera dalam mengelola keuangan keluarga, walaupun awalnya mereka sempat putus asa karena kurangnya ketelitian dalam memahami konsep dari pembukuan tersebut. Namun dengan kesabaran mentor dan ketekunan para peserta maka manfaat pelatihan soft skill ini dapat diterima dengan baik. Program inkubasi terbukti dapat meningkatkan bakat kewirausahaan sebagai faktor terpenting dalam pembentukan bisnis baru (Galvão et al., 2018; Kitagawa \& Robertson, 2015; Markowska, 2018; Neumeyer \& Santos, 2018; Swayne et al., 2019).

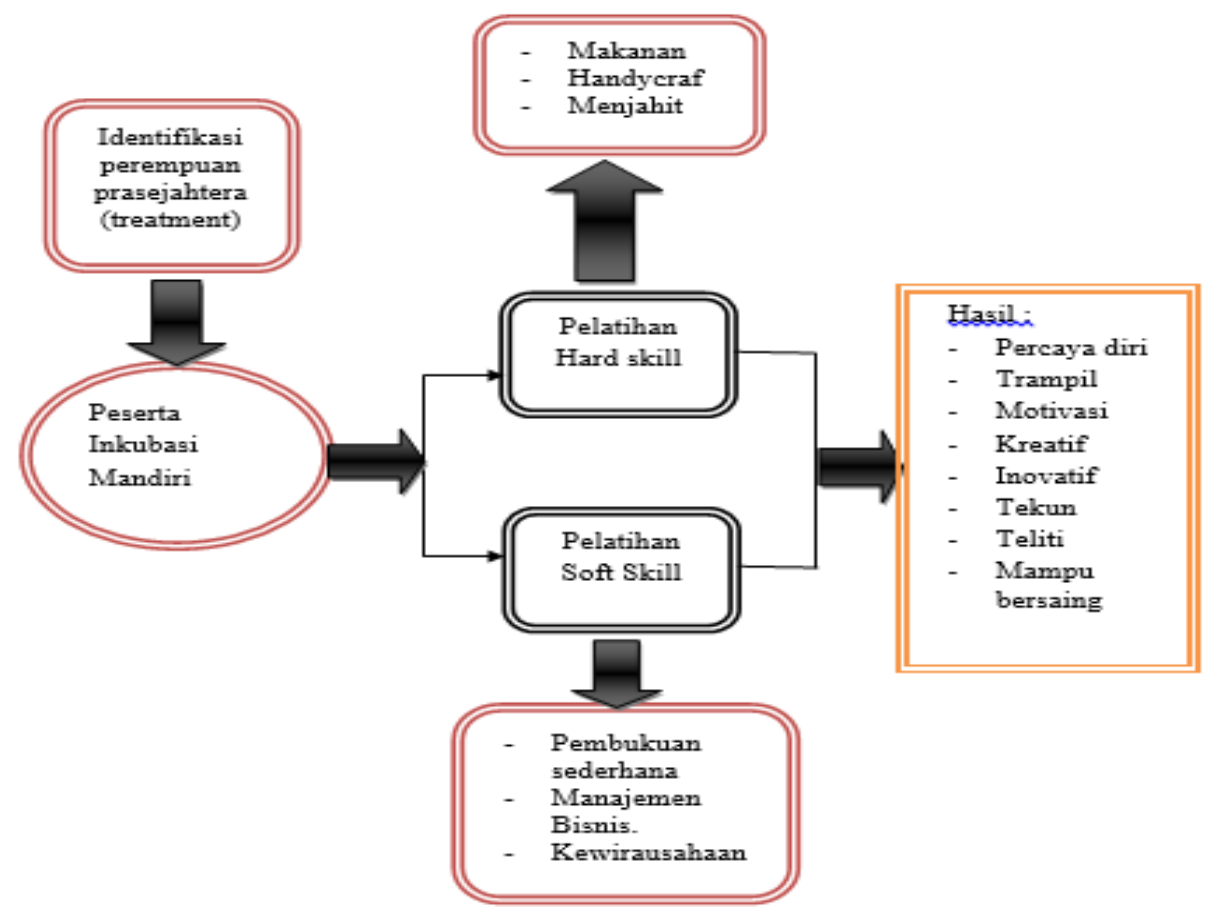

Gambar 3. Model Pemberdaya Perempuan Prasejahtera untuk Meningkatkan Penghasilan Keluarga 


\subsection{Inkubasi Meningkatkan Kemandirin dan Penghasilan Masyarakat}

Setiap wilayah telah terwakili informan yang dapat memberikan jawaban atas penelitian, semua informan adalah pelaku utama dalam kegiatan inkubasi dan informan juga merupakan kunci utama dalam memberikan informasi karena keaktifan informan dalam mengikuti kegiatan inkubasi. Informan juga menjadi Koordinator kelompok sehingga mudah untuk mengetahui kendala maupun pendekatan-pendekatan dengan peserta inkubasi lainnya.

Menurut informasi yang di dapat dari ketiga narasumber, peserta yang mengikuti pelatihan inkubasi mencapai 30-40 orang dalam hal ini ibu-ibu rusun Pesapen ikut bergabung dengan ibu-ibu rusun Dupak Bangunrejo. Hal ini menunjukkan bahwa antusiasme tinggi ibu-ibu rusun dalam mengikuti pelatihan ini. Namun, dalam pertemuan selanjutnya, peserta lama-lama menyusut hingga menyisakan sekitar 20 orang saja yang mengikuti pelatihan ini. Hal ini disebabkan karena beberapa faktor, yaitu masalah waktu dan tenaga serta masalah cuaca.

Faktor waktu dan tenaga mempengaruhi tingkat kehadiran ibu-ibu rusun karena mereka lebih memilih untuk menjaga anak-anak mereka dengan alasan tidak ada yang membantu menjaga sedangkan untuk faktor cuaca menjadi faktor utama yang mempengaruhi tingkat kehadiran ibu-ibu rusun. Hal ini disebabkan karena, dengan cuaca yang tidak bersahabat di Surabaya, ibu-ibu rusun menjadi kendur semangatnya dalam membuat kerupuk. Bahkan ada yang tidak berani mengikuti pelatihan, karena belum mempraktekkan membuat kerupuk disebabkan cuaca yang tidak mendukung. Ibu-ibu rusun menjadi sungkan apabila datang pelatihan tapi tidak membawa hasil praktek sesuai apa yang dijanjikan dan dipelajari pada saat pelatihan. Kendala yang dihadapi ini tidak jarang membuat peserta inkubasi melakukan inovasi agar usaha mereka tetap jalan.

Setiap pelaku usaha selalu mempersiapkan strategi khusus untuk menghadapi persaingan pasar dan merebut konsumen dalam rangka meningkatkan penjualan sesuai dengan target yang ditetapkan. Membuat produk unggulan menjadi salah satu langkah yang ditempuh agar suatu produk usaha menonjol di pasar. Produk unggulan menawarkan added value sehingga memiliki positioning dan dapat dikategorikan sebagai produk atau jasa unggulan (Hadiyati, 2011; Healy \& Dwyer, 2018; Pelletier \& Cloutier, 2019).

\subsection{Inovasi yang Sudah Dilakukan}

Sekelompok warga rusun telah melakukan inovasi terhadap produk-produk yang dihasilkan misalnya dalam pembuatan brownies dengan varian rasa. Seperti yang disampaikan oleh salah satu peserta inkubasi mandiri ibu Winarti,

"sebenarnya yang buat beda iku,,,bahannya, untuk jenis ini saya pake ketelo pengganti tepungnya,dan gak pake pengawet, rasanya gak kalah enak bu, lumayan banyak yang suka, pesanan yaa tiap minggu adalah bu..."

Menurut peserta, brownies dangan bahan baku yang berbeda mimiliki cita rasa yang berbeda. Sedangkan untuk produk lain seperti krupuk, juga menghasilkan inovasi berbeda dengan merubah bentuk krupuk yang biasnya dijual di pasar, tentu dengan mengganti bentuknya dan warna akan memiliki inovasi yang berbeda sehingga orang menjadi tidak bosan karena bentuk yang unik, contohnya krupuk samilir yang biasanya besar-besar dibuat munggil sehingga akan memudahkan yang mengkonsumsi, terutama kaum milineal yang enggan makan kerupuk tradisional, dengan bentuk yang berbeda tentu akan menarik perhatian kaum milineal dan menyukai produk tradisional. Hal ini diperkuat oleh pernyataan ibu Sarofah. 
"krupuk itu asline yoo kabeh seneng,,jareku,,hehehe,,tapi anak-anak muda iku lebih seneng ambe produk-produk sing akeh micine,,opo jenenge chikichiki,,,tapi setelah samiler iki dicilikno bentuknya,yooo podo seneng padahal cuman dikecilno tok, yoo karena makannya ora susah..."

Hasil survei dilapangan menunjukkan inovasi yang sudah dilakukan dalam kegiatan program inkubasi Klinik Usaha Mandiri berupa motivasi untuk berinvestasi pada peralatan masak maupun motivasi dari segi pemasaran. Beberapa ibu-ibu rusun sudah membeli oven sendiri karena termotivasi untuk belajar mempraktekkan membuat brownies sendiri. Hasil karya membuat brownies juga mulai dipasarkan di sekitar rusun, toko-toko terdekat bahkan sudah merambah ke pameran kantor kelurahan terdekat sehingga hasil penjualan brownies tersebut dapat menambah penghasilan ibu-ibu rusun. Hasil karya membuat keripik semiler juga mulai dipasarkan ke toko-toko terdekat meskipun hasil yang di dapat lebih kecil daripada penghasilan penjualan brownies. Selain itu, inovasi juga dilakukan pada diferensiasi produk. Beberapa hasil inovasi antara lain seperti samiler mini yang digemari anakanak dan kaum milineal, juga orang dewasa pada umumnya, dengan diferensiasi pada bentuk yang mini. Inovasi juga dilakukan pada pembuatan kue brownies dari bahan telo, kebaharuan dari bahan baku pengganti tepung dan tidak menggunakan pengawet.

Pelatihan menjahit juga diberikan selain membuat kue dan krupuk, tentu dari semua peserta tidak semua yang memiliki kemampuan dalam menjahit. Kemampuan menjahit membutuhkan keterampilan dan seni, karena selain menjahit juga diajarkan membuat pola dan merancang baju. Melalui kegiatan pelatihan menjahit tersebut, diharapkan akan memberikan keuntungan bagi Ibu-Ibu baik secara non material maupun material. Keuntungan non material yang diperoleh diantaranya kemampuan menjahit sendiri bisa memiliki pakaian baru, rasa bangga karena hasil bisa dinikmati sendiri, penghargaan dan kepercayaan dari orang lain.

Keuntungan secara material yang diperoleh dari pelatihan menjahit diantaranya keterampilan baru yang dapat dijadikan sebagai pekerjaan. Khusus pada keterampilan menjahit, peminat dari peserta inkubasi tidak banyak, minat untuk mengelola bisnis jahit tidak terlalu di minati, terlihat dari tingkat kehadiran ibu-ibu rusun yang menurun. Jumlah peserta pada hari pertama, kedua, ketiga, dan keempat tidak stabil karena beberapa peserta yang kehadirannya tidak rutin (ada peserta yang setelah menerima kain belum sempat dipotong sesuai pola sudah tidak ingin mengikuti pelatihan lagi). Salah satu informan yang kurang minat yaitu ibu Rukiyati:

“...kalau jahit gak langsung dapat duit, beda mbak kalau jual gorengan bisa langsung dapat uang terus muter duitnya,,,kebutuhane akeh lhaa lama muter duitnya le jahit dan aku yooo kurang minat sejak awal jadi milih ikut sing olah makanan"

Minat dalam menjahit diawal memang kurang diminati namun keterampilan ini jika ditekuni akan memberikan pendapatan yang bagus dibandingkan hanya menjul gorengan atau sekedar membuat kerupuk, seperti yang dialami oleh ibu Dian:

"..harus sabar memang mbak,,, menjahit itu awalnya memang dapatnya gak banyak, apalagi kalau belum dikenal orang, tapi kalau sudah cocok yaa dicari orang, kadang dikasih order dari konveksi-konveksi untuk jahit baju seragam sekolah, seragam kantor,,,dapatnya lumayan mbak, sekarang saya sudah punya 3 mesin dan punya satu orang asisten mbak yang awalnya tak kerjain sendiri.." 
Para peserta inkubasi mandiri khususnya menjahit memang beraneka ragam sifatnya, karena faktor internal peserta yang kurang mendukung dan tidak adanya motivasi, namun beberapa peserta mampu mengikuti keterampilan tersebut dan berhasil.

\section{SIMPULAN}

Kegiatan program Inkubasi Klinik Usaha Mandiri perempuan prasejahtera yang tingal di rusunawa dapat membawa manfaat pada peningkatan ekonomi keluarga. Tantangan dalam melakukan pemberdayaan perempuan berasal dari berbagai faktor, antara lain tidak mau meninggalkan pekerjaan, menjaga anak, usia lanjut dan malas. Pemberdayaan wanita di rusunawa dapat meningkatkan kemandirian perempuan dan penghasilan keluarga. Disamping itu, inovasi juga dapat berkembang pasca inkubasi dengan komitmen yang ditunjukkan seperti berinvestasi pada perlatan dan perlengkapan untuk mengembangkan bisnisnya. Produk hasil karya ibu-ibu rusunawa mulai dipasarkan ke wilayah terdekat bahkan sudah mengikuti pameran dan merambah ke kantor kelurahan dan kecamatan terdekat. Hal ini membuktikan perempuan prasejahtera mampu bersaing di dunia pekerjaan/bisnis dan outcome pun tercapai yaitu adanya peningkatan penghasilan dalam membantu keluarga.

\section{REFERENSI}

Adegbite, O. (2001). Business Incubators and Small Enterprise Development: The Nigerian Experience. Small Bussiness Economics, 17, 157-166.

Aernoudt, R. (2004). Incubators: Tool for Entrepreneurship? Small Bussiness Economic, 23, 127-135.

Andrian, B., Ghina, A., Prodi, S., Bisnis, M., Ekonomi, F., \& Telkom, U. (2015). Analisis Perkembangan Alumni Tenant Setelah Proses Inkubasi ( Studi Kasus Pada Bandung Digital Valley 2015 ). E-Proceeding of Management, 2(2), 11791189.

Cassells, S., \& Lewis, K. V. (2017). Environmental management training for micro and small enterprises : the missing link? Environtmental Management Training, 24(2), 297-312. https://doi.org/10.1108/JSBED-09-2016-0145

Ciptosari, F., Prabawa, T. S., \& Antonius, B. (2019). Social Capital Dalam Kewirausahaan Lokal Kajian Keterlibatan Masyarakat Dalam Usaha Pariwisata Di Delha Kabupaten Rote Ndao Nusa Tenggara Timur. Jurnal Kawistara, 9(1), 45-59.

Citra, I. P. A. (2017). Strategi pemberdayaan masyarakat untuk pengembangan ekowisata wilayah pesisir di kabupaten buleleng. Jurnal Ilmu Sosial Dan Humaniora, 6(1), 31-41.

Fiegenbaum, A. (2015). The Take-off of Israeli High-Tech Entrepreneurship During the 1990s.

Galvão, A., Marques, C., \& Ferreira, J. (2018). Entrepreneurship education and training as facilitators of regional development A systematic literature review. Jurnal of Small Bussiness and Enterprise Development, 25(1), 17-40. https:/ /doi.org/10.1108/JSBED-05-2017-0178

Hadiyati, E. (2011). Kreativitas dan Inovasi Berpengaruh Terhadap Kewirausahaan Usaha Kecil. Jurnal Manajemen Dan Kewirausahaan, 13(1), 8-16.

Handayani, N., Ardini, L., \& Damayanti, K. (2016). Self-Help Groups ( Shgs ) Potential And Strategy In Increasing Local Product Quality Through Sub-. International Journal of Management and Applied Sciences, 2(1), 19-24.

Healy, B., \& Dwyer, M. O. (2018). An exploration of product advantage and its 
antecedents in SMEs advantage. Journal of Small Bussiness and Enterprise Development, 25(1), 129-146. https://doi.org/10.1108/JSBED-06-2017-0206

Kitagawa, F., \& Robertson, S. (2015). High-tech Entrepreneurial "Soft Starters" in a University-Based Business Incubator: Space for Entrepreneurial Capital Formation and Emerging Business Models. New Technology-Based Firms in The New Millenium.

Markowska, M. (2018). The role of action-control beliefs in developing entrepreneurial expertise. Journal of Small Bussiness and Enterprise Development, 25(2), 222240. https://doi.org/10.1108/JSBED-05-2017-0180

Neumeyer, X., \& Santos, S. C. (2018). Entrepreneurship ecosystems and women entrepreneurs: a social capital and network approach. CrossMark. https://doi.org/https://doi.org/10.1007/s11187-018-9996-5

Entrepreneurship

Pelletier, C., \& Cloutier, L. M. (2019). Conceptualising digital transformation in SMEs : an ecosystemic perspective. Journal of Small Bussiness and Enterprise Development, 26(6), 855-876. https://doi.org/10.1108/JSBED-05-2019-0144

Permatasari, I. rifiani, Utoyo, S., \& Sulasari, A. (2016). Penguatan Karakteristik Wirausaha Berbasis Inkubasi Inovasi untuk Keberhasilan Usaha Mahasiswa PMW di Politeknik Negeri Malang. Prosiding Seminar Nasional Multi Disiplin Ilmu Unisbank, 978-979.

Suarsa, P. W., \& Sutajaya, I. M. (2015). Ergo-Entrepreneurship Untuk Mengembangkan Meningkatkan Pendapatan Pedagang Kuliner Lokal Di Desa Peliatan, Ubud, Gianyar. Jurnal Ilmu Sosial Dan Humaniora, 4(2), 609-622.

Suharto, E. A., \& Sugito. (2019). Pemberdayaan Usaha Mikro, Kecil dan Menengah Melalui Program Inkubasi Bisnis di Rumah Kreatif Badan Usaha Milik Negara Kota Yogyakarta. Jurnal Pendidikan Luar Sekolah, 8(5), 444-452.

Swayne, N., Mccarthy, S., \& Fisher, K. A. (2019). Uncoupling innovation and entrepreneurship to improve undergraduate education. Journal of Small Bussiness and Enterprise Development, 26(6), 783-796. https://doi.org/10.1108/JSBED-04-2019-0122

Telagawathi, N. L. S. (2017). Pberdayaan Usaha Kecil Dan Menengah Kain Tenun Cepuk Di Kecamatan Nusa Penida Kabupaten Klungkung, Bali. Jurnal Ilmu Sosial Dan Humaniora, 6(1), 1-9.

$\mathrm{Xu}, \mathrm{L}$. (2010). Business incubation in China to tenant enterprises. Management Research Review, 33(1), 90-99. https://doi.org/10.1108/01409171011011599 


\section{Halaman ini sengaja dikosongkan}

